Proceedings

\title{
Imagination as an Educational Tool for Teachers. The Development of Emotional-Relational Skills through the "Landscape Narration" Method +
}

\author{
Paola Damiani * and Filippo Gomez Paloma \\ Dipartimento di Scienze Chirurgiche, Università di Torino, 8-10124 Torino, Italy \\ * Correspondence: paola.damiani@unito.it; Tel.: +339-1018199 \\ + Presented at the International and Interdisciplinary Conference IMMAGINI? Image and Imagination \\ between representation, communication, education and psychology, Brixen, Italy, 27-28 November 2017.
}

Published: 4 December 2017

\begin{abstract}
This contribution is part of a borderline field between different disciplines, such as: pedagogy, psychology and arts. From the identification of the quality of the educational relationship and of the emotional-relational competence of teachers as variables determining the quality of the teaching-learning processes, the characteristic dimensions and the needs for specific training are highlighted. These dimensions, which concern the sphere of the "being" rather than that of skills and knowledge, are still underestimated and not properly valued within "traditional" training paths. The article seeks to offer a reflection in this direction and some information about the development of an "original" training device, based on reflexive and narrative modes but integrated with methodologies that can also enhance personal and implicit personal dimensions, aimed at change of dysfunctional attitudes.
\end{abstract}

Keywords: teacher training; skills; emotions; relationship; imagination; telling; picture; symbolic landscape; embodied cognition

1. Introduction: The Quality of Educational Relationships at School: An Unresolved Problem for Teachers Training

As stated in the literature, the quality of the teacher-student relationship is a key element of the quality of the school learning environment [1-3]. However, it needs to point out that the concept of quality itself needs to be studied in order to understand and improve the relational dynamics that are actually realized at school every day; in no way the quality of relationships in educational contexts can be taken for granted. Recent pedagogical literature is investigating the often hidden and subliminal dysfunctional phenomena of the educational-student relationship, particularly in relation to the inclusion or exclusion processes at school. In fact, concepts such as "micro-exclusion" [4] and "false inclusion" [5] have been discussed and described as push out and pull out phenomena [6], in order to make these anti-educational and anti-evolutionary relational dynamics clear and treatable. All studies and researches, also related to different disciplines, converge in highlighting the essential role of the teacher's personal skills [7-11], in order to make possible the building of empathetic, effective and inclusive educational relationships and, consequently, the achievement of a positive class climate.

In 2012, the European Agency for Special Needs and Inclusive Education developed the profile of the inclusive teacher through a mixed structure based on a complex concept of professional competence. This model reaffirms (in line with other models in the literature) the importance of personal dimensions like attitudes and opinions. As Ianes [12] points out, the attitude-a concept 
that is difficult to define-includes emotional experiences, values, motivations, and is a key variable for teachers' competence building.

Beyond the teacher's profile models, Caldin [13] points out that the same didactics should be understood as a training place, in which also the attitudes and mental representations of those who teach are to be taken care of.

It is therefore necessary to focus on the teacher's "being" dimensions, being them more complex and deeper than the dimensions of skill, communication and relationship that are usually taken into consideration. The ability to feel their own and others' emotions and the ability to build relationships of trust and mutual recognition are essential conditions for the achievement of a positive class climate and of an educational relationship with every single student. These are personal skills that professionals must possess, as required by institutional profiles, but which are in fact still misunderstood and underestimated in teachers, unlike what happens with healthcare professionals, for example [14,15].

It is therefore essential to strengthen the affective, emotional and relational skills of teachers in the initial and on-going training paths through appropriate, innovative, transdisciplinary approaches able to achieve profound aspects too. These paths must be complex, integrated and interdisciplinary; in fact, the spaces of relational dynamics include psychological and pedagogical spaces, but also social, cultural and material spaces and their objects, which must be made conceivable, describable and improvable through generative creative processes.

Research and training should be therefore converging for developing innovative transdisciplinary training devices. It is now clear that traditional training paths - whether they're initial or in-itinere-are often not adequate to promote an authentic change of deep mental attitudes and abilities; Specialized and multi-qualified teachers, as well as the less experienced ones, in their daily work with students, almost always deal with emotional and relational problems, rarely of a disciplinary or technical nature.

The pedagogical device [16-18] is recognized as a suitable complex training device: "It is a network organization of times, spaces, bodily dimensions, activities, signs and symbols, media and materials, which somehow shapes an educational situation" [18], p. 30.

\section{The Role of Beliefs: Conscious and Implied Systems in Teacher-Student Relationship}

Studies on teachers' training, also in light of the ten-year experience of initial university training and internships, have highlighted the significant role played by the system of beliefs in building a professional identity and choosing the daily actions at school. According to Munby, Russel and Martin's model [19], the pedagogical choices on which teachers base their professions are related to a system of knowledge which includes: beliefs, practices, theories on pedagogical practices, and specific knowledge. As Fiorilli recalls [20], this extensive system would act as a knowledge filter model and would include three levels of teachers' beliefs: expressive beliefs, rooted beliefs or convictions, and manifested or enacted beliefs (which are not aware).

In literature, in addition to the prevalence of such conscious and implied systems of professional functioning, their persistence is identified as a critical aspect: the abandonment of a belief clashes with many elements, mainly with its unaware character. Indeed, every individual implicitly uses his beliefs to know about and act in reality. Teachers' beliefs will be relatively stable and resistant to change, especially if they have a central position in the subject' system of knowledge [21-23]. So promoting training processes for changing relational attitudes and teaching styles means dealing with dynamics related to role identity.

The change in beliefs cannot be seen only as a transformation through a process of accommodation where pre-existing beliefs are reshaped and find meaning in experience, but it must involve the social dimension (within which the theme of recognition seems to be a priority). In fact, it is not uncommon for old beliefs to coexist with new knowledge, realizing a formation that is information without trans-formation. 


\section{Improving the Quality of Relationships: A Research-Training Project for Teachers}

The PhD research of the author [24] was focused on the design and development of a training path for teachers, consistent with the above-mentioned framework. The experiment, carried out in the academic year 2009-2010 at the University of Turin and with a duration of a whole school year, saw the participation of three groups of school teachers of different order in a research-training path aimed at enhancing self-awareness, beliefs and attitudes in the relationships with students, through reflection and narration on/about the above-described profound dimensions.

More specifically, the objective of the work consisted in the upgrading/training of the relational mental space of the teachers in terms of "field of relational imagination", within which even implicit, non-verbal/pre-verbal and unconscious profound dimensions could find their place in a peer support community context. The theory underlying the research stated that this could have improved the quality of relationships at school, with particular reference to the relationship between teachers and students. Two conceptual models were used to identify the idea of relational quality: Edgar Schein's model and Boszormenyi-Nagy's Relational Ethics theory [25]. Both models converge on the importance of values of trust, recognition and fairness/reciprocity, values that are directly involved in people's attitudes and abilities of relationship.

According to Schein [26], it needs to describe the specific elements to try to understand what it means to "have a good relationship", meaning with it the relationship in which we can trust each other and communicate openly. The author states that the essence of the relationship is based on two fundamental principles: (1) The communication between two subjects is a process of reciprocal interaction that must be fair and equal; (2) The relationships in human culture are based on prescriptive roles that we learn to play from early childhood, of which we have no awareness. These roles must be complementary. Schein uses the concept of "social economy" to describe the rules of fairness and reciprocity that define the culturally determined way in which we assess each other within relationships. The "social coins" that are exchanged are love, attention, recognition, acceptance, praise and help. The latter represents one of the most important coins as it allows showing love, attention, recognition (thus conveying other social coins) and other positive emotions, and constitutes the "work object" of the relationship network's professionals of which teachers, in a more or less aware way, are part of $[5,26]$.

Boszormenyi-Nagy, in a different field than Schein, develops a therapeutic model for the rehabilitation of relationships in multiple discomfort situations, by involving the feeling of loyalty, and recognition of the concern for the "other" as ethical values that are somehow in all of us, on which to leverage the rebuilding of networks of trust and support in collective contexts.

According to these models, the development of "quality relationships" which, as we have seen, needs specific personal skills, is based on the ability to recognize and draw on one's own personal resources, be in contact with one's own inner world, manage and enhance profound emotionalaffective (non-verbal) dynamics, through identification, recognition and narrative paths, together with/through others.

The challenge therefore lies in not initiating clinical group therapy interventions in training contexts, as well as in developing devices that favor the development of the relational mind [27] and the ability to think and imagine "genuinely" educational, ethical, and inclusive relationship perspectives as essential aspects of the teacher's personal skills.

The approaches examined show the path to the reconstruction of individuals' stories and "problematic cases" in the light of bonds and relationships with other people (which may be present, absent, evoked, imagined) in the collective space of life and work, as valorization of the potentialities and resources of people and contexts. The collective support then allows for the re-reading of everybody's facts and mental positions (opinions, attitudes ...) in order to change for reaching an improvement, in terms of preventing burnout [28] and reciprocal empowerement, as well as recently demonstrated by evidence based research $[29,30]$. 


\section{Dimensions of the "Being" and Theories of Change: What Educational Models}

Accompanying teachers in a process of genuine change in their attitudes and their ways of being in the relationship with the students is not a simple path, and it cannot be achieved with simple and "classic" training methodologies. The reflection on the nature of the change, specifically in our research, intersects the areas of cognitive, neuropsychological and psychoanalytical sciences and, more recently, neuroscience [14,15].

As highlighted by Bara [31], the optimal change model refers to a profound change: it is a change involving the inner structure of the person; today, we would add that this change affects all the aspects of a person's personality and relationships with the contexts, according a biopsychosocial perspective. In the cognitivist model, the precondition of change is that you don't change if you are not able to be yourself: the mature (healthy) structuring of yourself is the conditio sine qua non. The self-consciousness allows for the change and makes it possible to think beyond the self, think about the other and his wellbeing. The dimensions involved are those of metacognition, reflexivity and awareness.

The full development of cognitive skills allows building a model of one's own model of cognitive and emotional functioning, and thus of the relational mind. The metacognition on knowledge is based on the ability to recursively apply the thought to oneself, gaining awareness of one's own main ways of organizing knowledge: to think, to remember, to decide. The metacognition on the emotions allows self-observing and self-adjusting one's own emotional style by observing the stable pattern of emotion, particularly that of conscious emotion that Damasio [32] calls "feelings".

Within this framework, the transformation of Metacognitive beliefs goes through reflexivity understood as a process that makes clear the nature of belief and their differences with who [31,33]. Develop thinking reflectively involves the use of a specific process given by reflective abstraction; It is realized through metacognitive processes to reflect on themselves, on their teaching strategies and beliefs about themselves. Develop thinking thoughtful means also activate a layer metacognitive thinking itself which becomes conscious of its causes and its consequences [34]. The training model based on reflexivity outlines a life-long education based on self-regulation, self-assessment and comparison with others in order to facilitate mutual recognition, appreciation of differences and experimentation with new conditions of teaching [35,36]. The change never occurs alone, but it always takes place in the relationship. It is thanks to the participation in a community or group with whom practices are shared that conceptual changes may have more chance to be realized [20], p. 40.

However, awareness and metacognitive ability do not exhaust the possibilities for evolution and change; reflection and metacognition do not automatically guarantee or determine the changing behavior and attitudes, people's emotional and cognitive systems. There are other forms of change that don't go through awareness (imperfect or implied change), but that have significant developmental and educational value: some processes or elements of the learning and development process are favored by pre-reflective, pre-verbal or non formulated experiences $[37,38]$ in a fruitful exchange between dimensions of different levels.

In psychodynamics, Winnicott [39] stresses that the inner reality is constantly compared to models of external or shared reality. In the transitional area of experience, the ability to enter into relationship with objects, based on an exchange between external reality and models of personal psychic reality, is reflected in the use that the child makes of symbols, in the creative game and in the gradual ability to use the cultural potential to the extent that it is available in the surrounding social environment. This process defines the establishment of relationships based on projection and introjection mechanisms.

Recent psychoanalytic perspectives highlight a different function of consciousness: it doesn't have to enlighten dark parts, but it has to attach meaning to wrong setting function, at intra-psychic or interpersonal level. The centerpiece of the shift is not consciousness, but the direction of the regulation through the modification of the subject or context representation systems which form the basis of an incorrect regulation intervention [40].

Every relationship we have is framed in an affective relationship of unconscious nature [41]. Psychotherapy, to be effective, must combine supportive relational functions (real aspects of 
relationships) with expressive functions (symbolic processing) which can be found both in the transferential aspects of relationships: the relationship of treatment must be combined with the working alliance and the analysis of unaware contents.

If the transferability of transference dynamics is applied to any significant relationship [42] the criteria for the effectiveness of the change processes in the relationship must be referred to all its mechanisms, even those non-verbal, implicit and affective. The two levels dynamics of the change and relational process, within which the change takes place and which is symbolic and concrete, is a valued strategic reference for reflection on the profound mechanisms of change, also in the educational setting.

Improving the quality of relationships in school cannot be fully realizable by only working on intentional, rational and cognitive dimensions. It needs to promote paths of thought and metacognition on professional experience (in our specific case, the relational one) that are flexible enough, meaning that they are able to see and retrieve all the complex and deep dimensions involved, beyond those cultural, cognitive and referred to abilities. It also needs to think about the experience not yet realized, on what is possible and what is not possible yet, in order to enhance the present but not remaining anchored to it; It also needs to include dimensions that are inexpressible, unthinkable and imaginative in order to restore and enhance the integrity and complexity of oneself and of the existential experiences (primarily the relational one).

A current study and research perspective, coherent whit framework showed, is the Embodied Cognition [14,43]; our effort is to identify a current and systematic approach to improving the "new integrated skills" of teachers and students.

\section{A Proper Training Approach: "The Recovery of the Complex Experience" through Narration}

Psycho-pedagogical literature has long highlighted the importance of starting up training courses focused on narration and on the personal/professional autobiography, able to support the integrity of the sense of the self to facilitate the deep and authentic change in one's own way of being $[44,45]$. The narrative experience arises within a transdisciplinary field and is characterized as a methodology for learning from experience that lends itself to the care of aspects of integration and broadening.

As evidenced by Smorti [46,47], narrations are reports of other texts concerning the action within a contextual "block" consisting of agent, tool, purpose and scene or "pieces" of the world), in some cases known and acted directly by the subject [48] and, in other cases, only imagined or reported, on which it is possible to develop other texts. The author invokes the concept of "distributed self" worked out by Bruner, referring to the fact that the self is not only inside the person but also outside of it, namely in those parts of the world that the narration brings "inside" the subject. The narrative thought is the way of thinking that allows for the construction of interpretative models of reality ... the narrative constructions can only achieve verisimilitude; possible versions of reality whose acceptance is ruled by the convention of the narrative need and not by the rational certainty.

If we consider the relationship between teachers and students as a complex relational experience, characterized by multiple elements (implicit, symbolic, emotional, cognitive and linguistic), some of which can escape or remain "non-treatable", the training work consists in attaching meaning to the various "pieces" of the experience, within a narrative plot that is constructive, ethical and aesthetical. The reconstruction of a history provides meaning and continuity to the self that is embodied in the history itself, and that participates in the narration with his whole mind and body, in line with an Embodied approach of knowledge and development [49-51] in the intersubjective and relational experience [52].

Starting from these considerations, a narrative device of research-training was developed, which aimed at the promotion of changing attitudes of teachers, able to recover and enhance the implied, emotional, nonverbal and verbal dimensions of the relational experiences with students through the exchange and comparison between colleagues, and we will try to briefly describe its characteristic elements in the following paragraphs. 
The Construction of an Original Device through the Integration of the Imaginative and Unconscious Dimension: The "Landscape Narration" Method

The overall structure of the experimentation carried out with teachers can be succinctly explained as follows:

- $\quad$ Research problem. How to foster/improve the quality of relationships between teachers and students in order to promote wellness and classroom learning?

- Research hypothesis On the basis of the theoretical framework, the strategies to improve the quality of relationships between teachers and students need to stimulate: (1) The strengthening of the teachers' reality testing abilities (reflexive and metacognitive competence); (2) the development of teachers' awareness towards implicit and unconscious emotional-relational and cultural dimensions, at personal and contextual level; (3) the consequent change in the teachers' relational attitude, in his characteristic dimensions (beliefs, feelings, perceptions, ambivalence and perception of significance). According to the theory underlying this research, in fact, the focus on this dimension represents an element of facilitation and improvement of the quality of relationships at school, and consequently working life and teaching-learning processes quality.

- Target Three groups of teachers from different school orders (45 teachers in total, among upper and lower secondary school teachers).

- Stages The experimental process with teachers, which lasted one year (except to the follow up/monitor stage made at the beginning of the following school year), has been divided into five stages corresponding to five meetings, during which imaginative and expressive dimensions were gradually introduced (beyond that verbal one), and the has been a shift in the focus of the narratives from "problematic" cases, coincident with the critical characteristics of students and/or of the "colleague-problem "the complex", to the "stories" in which everyone was coprotagonist. Such "enrichment", which must first be conceived and then lived, were made possible by the use of narrative technique of landscape worked out by Gallo Barbisio, who developed a transitional tool to make the exploration of new elements and new spaces of the relational experience, in a training context, sustainable.

- -Methodologies and tools. Although sharing theoretical frameworks and methodological principles with other training models, the training of in-service professionals takes on distinctive features that require specific actions. The path with the teachers has been configured as a research-action and research-training of experiential and partnership nature, within which different methodologies have been used for the development of the original integrated device.

The main educational tool is composed of the working group, being it the medium and purpose of the training process. The educational group represents the place of "clashes and learning" through which to gain expertise and widen one's own individual and collective existential abilities [53]. The group proves to be also instrumental in putting into light and managing different relationalcommunicational dimensions, the specific object of the experimentation since it is a "condition" in which, through dialogue and discussion with other points of view, itis possible to learn how to learn from experience [54], making the discussion of events the drive for widening one's own understanding and for mutual enrichment [55]. The meaning is assumed in the group, but in the group itself it is changed; the discoursivity in the group is not static, but it is changeable and flexible and allows individuals to experience the ability to live the difference, to experience uncertainty, to tolerate disagreement, to change, to cooperate. We have integrated the work with the group, of reflective nature and fiction, with "original" educational strategies related to the model of the "landscape narration", in order to embrace and enhance deep emotional and embodied aspects, about which we will discuss later.

Synthetically, the innovative elements introduced with respect to training methodologies based on "traditional" narration and autobiography were:

(1) The focus on implicit and unconscious affective dimensions that characterize the relational experience, within a pedagogical and non-clinical training perspective. 
(2) The use of a pictorial and symbolic-type narrative methodology, which focuses on the imaginative dimension.

Those choices were consistent from a strategic, methodological and epistemological viewpoint, with the framework and with the training aims adopted by research and briefly discussed so far.

To realize this training device we chose to refer to the methodology of the landscape narration developed in psychodynamics by Gallo Barbisio [56,57]. The method makes it possible to enhance the formative role of narration and imagination through an integrated and integrating approach involving verbal and non-verbal dimensions, metacognition and pre-reflexive affectivity. It is based on the theory of educational and restrictive value of beauty, through the iconic and verbal expression of the imaginative space of teachers, and is aimed at the integrated representation of themselves in the relationship, in an aesthetical perspective of meaning and ethics of reciprocity.

This vision is coherent with recent neuroscientific approach, and the Embodied Cognition's perspective. Freedberg and Gallese [58] illustrate the neural mechanisms that underpin the empathetic 'power of images' and show that embodied simulation and the empathetic feelings it generates has a crucial role [p. 197]. "Automatic empathetic responses constitute a basic level of response to images and to works of art. Underlying such responses is the process of embodied simulation that enables the direct experiential understanding of the intentional and emotional contents of images" [ib. p. 202].

More specifically, during the second and third meeting, all the teachers have lived a "double" narrative experience: the verbal description of a meaningful critical situation (related to managing relationships at school), and the possibility of re-narrating, through other codes of expression, their relational landscape. This phase was particularly interesting and engaging: during the initial verbalization, the groups have reported almost exclusively the students' deficits and reductive lists of critical facts, showing monotonous and stereotyped visions focused on the "other-problem" in which they were absent contextual aspects. During the subsequent meeting, the journey into the imagination of one's own relational landscape has allowed for a wider viewpoint of the relational event, and the possibility of an authentic change.

In the drawing of the landscape there are all the elements of the relational experience at school, even the painful or untold ones (often characterizing the relationship with different, difficult students or students that are extremely hard to manage), in a form that is mediated by a transitional "experience" in a collective context of mutual recognition and support (the Group) and a transitional "improved and beautiful" object (the drawn landscape).

Concretely, the teachers were asked to imagine and describe the own professional landscape through a drawing or a painting depending on the technique they chose. Each of them had his own work with individualized ways and times; at the end, they were invited to express emotions and feelings with their body and/or other artistic modes (music, gestures ...), and then everyone started to reflect on what emerged and to reconstruct stories and meanings through verbalization. The group helped integrate elements and reveal meanings in a sort of meta-collective reconstruction. No teacher felt alone anymore and the personal story of each shaded over into the common story or into a kind of "collective care". Resources and solutions to individual difficulties were amplified in the collective mental space.

The imaginative view and the drawing of landscape elements (mountains, forests, rivers, paths, atmospheric agents) have been described as backgrounds, emotions, escape routes, traps, and perspectives of one's own way of being in a relationship, creating new awareness. From then on, in all the working groups, perceptions and ways of describing one's own relationships have changed and become more complex. The narration in the group has allowed for the sharing of a collective, at the same time aesthetic, experience (they all appreciated and enjoyed the beauty of the different drawings), educational (each one felt recognized in his own stories and free to introduce thoughts and elements to enrich the stories of the colleague's landscape, thus amplifying prospects) and ethical (all contributed to the realization of the landscape and to the identification of a contextual meaning, which was at the same time individual and collective, thus "useful" to the common good). Although born in the clinical field, the methodology employed is built on aesthetical and ethical values, with a 
strong educational connotation: imagination, utopia, beauty, hope, trust, planning and change. According to Gallo Barbisio [59], "Psychologists have to face very painful issues, sometimes their work can be stressful without a proper containment. This containment can come from the beauty, beautiful scenery, nature and arts. Beauty nourishes hope and faith in life and prevents everybody from falling into despair". In that sense, as shown by the author, the function of the narration of one's own landscape, introduced by psychoanalysis, is also used in education: through the "focus on the landscape" and not on oneself, it promotes greater freedom of expression. Free associations give rise to unconscious experiences within the framework of a personal, but also shared space, and allow giving shape to emotions, fears, desires in a third space where an emotional distancing is possible by avoiding direct involvement. In the narration of the landscape, reflexivity and awareness are accompanied by curiosity and an aesthetical dimension that "relieves" the burden of the on-going training process, and make pre-verbal and implicit personal elements accessible and recoverable in interpersonal context.

The imaginative research on one's own landscape is a research about the symbolic function and spaces of the mind that moves from one's own individuality, but that feeds and is complemented in the collective and social space through mechanisms of reciprocity. The mind expands its space of willingness to learn from experience $[42,60]$.

The theme of the arts of landscape care presupposes the human being's faculty of relationship with himself and with the universe surrounding him. The research on the landscape is a research on the symbolic function and on the spaces of freedom of mind. The "focus on the landscape "and not on oneself, according to the author, promotes greater freedom of expression; free associations shape unconscious experiences within the framework of an area, which is personal but also shared, and allow giving shape to emotions, fears, desires in a third space where an emotional distancing is possible by avoiding the direct involvement [59]. The narration and the analysis of representations of landscapes are realized in a dynamic space that is both individual and collective at the same time; real and imaginary facts are presented and represented with different attributions of meaning. The different versions of the landscape, imagined, narrated and represented, allow making comparisons, negotiations and transformations; by making different interpretations of the landscape, the interpretation becomes alive and creative.

The use of the construct of the unconscious allows grasping, in the narration of the landscape, the latent contents besides those manifested ones, and following the development throughout the evolution of the image of the landscape in relation to private and social events; from the cognitive point of view, the time reversibility, made possible in the narration, allows making reflections on the past and the future of the experience through anticipation and high-processing thought operations. The educational value of this approach, as well as the therapeutic one, becomes clear and real through the instrument of the landscape narration (which, being a third element acting as mediator, allows for greater freedom of expression) and the reflection about the "tales of personal landscape", which cannot establish itself as case studies in the traditional sense, helps shape one's own life experience by sorting it in space and time [ib. p. 20].

In perspective, we are interested to study the role of action and body movement in the teacher's training device as reinforcing strategies to improve emotional and empathic understanding. Use the hand to draw and move the body to represent the landscape, before telling it through language, starts embodied circuits that enhance thought and empathy, even through reciprocal observation [52]. Imitation is a "neurobiological training mode" that should be retrieved and systematized. 


\section{Concluding Considerations}

The element of originality and innovativeness is given mainly by the integration of strategies and elements belonging to different models: that psychodynamic, artistic and narrative autobiographical. This "chance" is in our opinion justified by the fact that only the development of a complex device allows following complex dynamics and trying to read and reconstruct the complexity of the relational experience at school, in a perspective of change.

In the model worked out by Gallo Barbisio, the landscape acts as a bridge between scientific and humanistic studies, and requires the formulation of reference theories that serve as structures and connection between the approaches of the different disciplines. The use of the categories of representation and narration of the landscape highlights educational implications: the function of narrating one's own landscape, already anticipated by psychoanalysis, finds application and usefulness in the educational field too.

Consistent with what was theorized, at the end of the experimentation, the teachers experienced an increase in awareness of their own relational experience, opening up to the possibility of real change of their deepest attitudes rooted in the exchange with others. Questionnaires, observations and ex post activities (monitoring and follow up phase) have allowed to detect differences in the beliefs and attitudes of teachers towards the relationships with their students. It was also observed a significant change in communication and narration modalities. Almost all teachers, in narrating relational processes before the experimentation, had used stereotyped and reductive narration patterns, focused on negative aspects or partial and prejudicial information. Teachers" initial attitude too, in terms of beliefs and feelings, was poor in elements of ambivalence, trust and hope characterizing the "good relationships".

The device developed for the in-service training for teachers of all levels, resulted to be functional to the improvement of the above-described abilities, and can "snap" all those dimensions of the being, which are part of the professional competences described in literature and outlined in the official documents of the school. So a complex device allows following complex dynamics and trying to read and reconstruct the complexity of the relational experience at school, in a perspective of change. The use of the landscape narration strategy has allowed to overcome the problem - wellknown in the literature-of the ineffectiveness of the social support experience of teachers in the burnout state, or in a situation of relational difficulty, since the change in attitudes and the building of trust and help/care bonds originate in the deepest and most primitive level of proto-change [61,62]. In conclusion, the device developed for the training of in-service teachers of every order and degree has proved functional to the achievement of the above-described objectives as it is able to "embrace" all those dimensions of the being, which are an essential part of the professional skills (described in the literature and specified in official school documents), but that are currently misunderstood. More specifically, results have been achieved both at the general level, on the development and upgrading of reflective and emotional-relational professional skills, and at a specific level, in the improvement of the ability to collaborate, in the perception of self-efficacy and self-confidence and in the group of colleagues (also through the identification of strategies for consolidating and sharing school-based training experiences), in dealing with difficult situations with students ("cases").

This latter aspect has represented a strength because-both during and after the experimentation - the teachers have set up their agency to co-build autonomously devices for maintaining and disseminating what they had learned with other colleagues belonging to their same school and, in some cases, with those belonging to other schools as well.

From an epistemological and methodological point of view, we are aware of the presence of some elements of criticality, both because of the complex and immaterial nature of the object of investigation, for which it is difficult to identify clear correlations and to detect empirical evidence, and because of the non-representativity of the sample. Starting from this experience, we are working out a system of indicators and descriptors, in order to detect and make some variables comparable and to allow for an expansion of the sample. 


\section{Outcomes: Tables}

In addition to the qualitative instruments of the investigation, quali-quantitative tools such as questionnaires or data gathering sheets have been employed by the teachers, both for a reflection and self-assessment, and for the assessment of the research path and of the outcomes. Here below, as an example, the outcomes of the self-evaluation questionnaire concerning the perception of relational and communicative skills of teachers before and after training which was administered to all the participating teachers before and after the experimentation (Questionario di autovalutazione delle competenze acquisite, Coggi, Ricchiardi, 2009). The data show a general and significant improvement in the perception of competence, as shown by pre-test data (Table 1) and post-test data (Table 2). Item n. 5 "Relational and Communicative Skills" was divided into 3 specific relational sub-skills:

(a) Listening to, observing and understanding students and their needs;

(b) Analyzing the pedagogical relationship;

(c) Managing the relationship with students and the interaction with them.

The assessment of the described skill occurs while attaching a score from 1 to 10 in ascending order, according to the degree in which it is thought to be achieved

Table 1. Outcomes Ex Ante administration (October 2009) - Total number of documents: 45.

\begin{tabular}{|c|c|c|c|c|c|c|c|}
\hline \multicolumn{8}{|c|}{ Item (a) } \\
\hline Score & 10 & 9 & $8 / 9$ & 8 & 7 & & 6 \\
\hline Number of answers & & & & 12 & 17 & & 16 \\
\hline \multicolumn{8}{|c|}{ Item (b) } \\
\hline Score & 10 & 9 & $8 / 9$ & 8 & 7 & 6 & 4 \\
\hline Number of answers & 0 & 0 & 0 & 2 & 3 & 22 & 18 \\
\hline \multicolumn{8}{|c|}{ Item (c) } \\
\hline Score & 10 & 9 & $8 / 9$ & 8 & 7 & 6 & 5 \\
\hline Number of answers & 0 & & 0 & 0 & 13 & 21 & 11 \\
\hline
\end{tabular}

Table 2. Outcomes Follow Up (Maggio 2010) - Total number of documents: 45.

\begin{tabular}{|c|c|c|c|c|c|c|}
\hline \multicolumn{7}{|c|}{ Item (a) } \\
\hline Score & 10 & 9 & $8 / 9$ & 8 & 7 & 6 \\
\hline Number of answers & & 4 & 11 & 20 & 10 & \\
\hline \multicolumn{7}{|c|}{ Item (b) } \\
\hline Score & 10 & 9 & $8 / 9$ & 8 & 7 & 6 \\
\hline Number of answers & 0 & 2 & 22 & 15 & 6 & 0 \\
\hline \multicolumn{7}{|c|}{ Item (c) } \\
\hline Score & 10 & 9 & $8 / 9$ & 8 & 7 & 6 \\
\hline Number of answers & 0 & 3 & 22 & 10 & 13 & 0 \\
\hline
\end{tabular}

These and other data have been read and commented on together with the work groups during the last monitoring meeting held in the following school year. All the teachers and school managers have been positively affected by the fact that the data evidence actually represented what they had developed in terms of awareness of the relational dynamics in progress, both in relation to the improvement of their management ability (self-efficacy), and in relation to the personal satisfaction and the perception of well-being experienced during the daily work with the classes after the experiment.

Further data have confirmed that the perceived difficulty in managing classrooms (the problems are always many) was the same, but the trust in their management skills and in peer support and context was greater. 
These outcomes are consistent with the process of increasing the ability to imagine and express different perspectives, and to identify new areas of reflection and resources for managing the relational complexity, which is realized through the experienced training device.

For the overall assessment of the path a perception questionnaire has been administered to the teachers and to the school managers, consisting of four questions based on the Kirkpatrick model, with the aim of investigating the levels of satisfaction; the perception of the learning level; the perception of its reflection in the classroom; the perception of its reflection at organizational level.

Author Contributions: Paola Damiani has prepared the training device and conducted experimentation with the teachers in the year 2009-2010. Paola Damiani and Filippo Gomez Paloma analyzed the device and data collected in light of the paradigm of Embodied Cognitive Science. Paola Damiani wrote the paragraphs (2-5); Filippo Gomez Paloma wrote the Introduction and the conclusion whit Paola Damiani.

Conflicts of Interest: The authors declare no conflict of interest.

\section{References}

1. Pianta, R.C. (Ed.) Manual and Scoring Guide for the Student-Teacher Relationships Scale; University of Virginia: Charlottesville, VA, USA, 1996.

2. Blandino, G. Psicologia Come Funzione Della Mente. Paradigmi Psicodinmamici per le Professioni D'aiuto; Utet: Novara, Italy, 2009

3. Altet, M. Caractériser, expliquer et comprendre les pratiques enseignantes pour aussi contribuer à leur évaluation. Les Doss. Des Sci. De L'éducation 2003, 10, 31-43.

4. Ianes, D.; Demo, H. Esserci o non esserci? Meccanismi di push e pull out nella realtá dell'integrazione Scolastica italiana. In Quale Scuola Inclusiva in Italia? Vianello, R., Di Nuovo, S., Eds.; Erickson: Trento, Italy, 2015.

5. Damiani, P. Un'idea di "Buona Scuola": La Scuola Estesa. Dalle prospettive emergenziali alle prospettive di sviluppo e di apprendimento “For All”. In Formazione E Insegnamento; 2016; XIV 2, ISSN 19734778, Pensa Multimedia: Lecce, pp. 137-144.

6. Demo, H. Dentro e Fuori Dall' Aula: Che Cosa Funziona Davvero Nella Classe Inclusiva? Ital. J. Spec. Educ. Incl. 2015, 3, 53-70.

7. Kahneman, D.; Tversky, A. Prospect Theory: An Analysis of Decision under Risk. Econometrica 1979, 47, 263-292.

8. Sheerens, J. Il Sistema degli indicatori del funzionamento della scuola. In Gli Indicatori Internazionali Dell'istruzione; OCSE-CERI; Armando: Roma, Italy, 1994; pp. 61-90.

9. Heckman, J.J. Causal Parameters and Policy Analysis in Economics: A Twentieth Century Retrospective. Q. J. Econ. 2000, 115, 45-97.

10. Heckman, J.J.; The case for investing in disadvantaged young children. In Big Ideas for Children: Investing in Our Nation's Future; First Focus: Washington, DC, USA, 2009; pp. 49-58.

11. Hattie, J.A.C. Visible Learning: A Synthesis of 800 Meta-Analyses Relating to Achievement; Routledge: Oxford, UK, 2009

12. Mitchell, D.R. What Really Works in Special and Inclusive Education: Using Evidence-Based Teaching Strategies; Routledge: Abingdon, Oxon, UK, 2015.

13. Ianes D. L'evoluzione Dell'insegnante di Sostegno; Erickson: Trento, Italy, 2015.

14. Caldin, R. Riflessioni sulla capacità di accogliere a scuola e nella comunità. In Cittadini in Crescita; Nuova Serie; Istituto degli Innocenti: Firenze, Italy, 2014; pp. 27-34.

15. Gomez Paloma, F.; Damiani, P. Cognizione Corporea, Competenze Integrate e Formazione dei Docenti. I tre Volti Dell'Embodied Cognitive Science Per Una Scuola Inclusiva; Erickson: Trento, Italy, 2015.

16. Gomez Paloma, F. (a cura di), Embodied Cognition: Theories and Applications in Education Science; Nova Science Publishers, Incorporated: New York, NY, USA, 2017.

17. Massa, R. La Clinica Della Formazione. Un'esperienza di Ricerca; Franco Angeli: Milano, Italy, 1992.

18. Massa, R. Le Tecniche e i Corpi; Unicopli: Milano, Italy, 1983.

19. Mantegazza, R. Teoria Critica Della Formazione. Espropriazione Dell'individuo e Pedagogia Della Resistenza; Unicopli: Milano, Italy, 1995.

20. Riva, M.G. Il Lavoro Pedagogico; Guerrini Scientifica: Milano, Italy, 2004. 
21. Munby, H.; Russell, T.; Martin, A.K. Teachers' knowledge and how it develops. In Handbook of Research on Teaching, 4th ed.; American Educational Research Assoc. V.: Washington, DC, USA, 2001; pp. 877-904.

22. Fiorilli, C. Gli Insegnanti Pensano L'intelligenza; Unicopli: Milano, Italy, 2009.

23. Kagan, D.M. Professional growth among preservice and beginning teachers. Rev. Educ. Res. 1992, 62, 129169.

24. Damiani, P. Apprendimento e Benessere: Le Dimensioni Implicite e Affettive Della Relazione Insegnante-Allievo: Progettazione e Sperimentazione di un Percorso Formativo Rivolto ai Docenti Per il Miglioramento Delle Qualità Relazionali a Scuola; Tesi di Dottorato, Università degli Studi di: Torino, Italy, 2011.

25. Boszormenyi-Nagy, I.; Spark, G. Lealtà Invisibili. La Reciprocità Nella Terapia Familiare Intergenerazionale; Astrolabio: Roma, Italy, 1988.

26. Schein, E. Le Forme Dell'aiuto; Raffaello Cortina Editore: Milano, Italy, 2010.

27. Blandino, G.; Granieri, B. La Disponibilità ad Apprendere: Dimensioni Emotive Nella Scuola e Formazione Degli Insegnanti; Raffaello Cortina: Milano, Italy, 1995.

28. Siegel, D.J. La Mente Relazionale; Raffaello Cortina Editore: Milano, Italy, 1999.

29. Albanese, O.; Lafortune, L.; Daniel, M.F.; Doudin, P.A.; Pons, F. Competenza Emotiva tra Psicologia ed Educazione; Franco Angeli: Milano, Italy, 2006.

30. Hattie, J.A.C. Visible Learning for Teachers. Maximizing Impact on Achievement; Routledge: Oxford, UK, 2012.

31. Bara, B.G. Dinamica del Cambiamento e del Non Cambiamento; Bollati Boringhieri: Torino, Italy, 2007.

32. Damasio, A.R. Emozione e Coscienza; Adelphi: Milano, Italy, 2000.

33. Joram, E.; Gabriele, A.J. Pre-service teachers' prior beliefs: Trans-Effects of educational culture and teaching experience on teachers' beliefs 95 forming obstacles into opportunities. Teach. Teach. Educ. 1998, 14, 175191.

34. Lipman, M. Caring as Thinking. Inq. Interdiscip. J. Philos. 2005, 15, 1-13.

35. Martin, D.; Doudin, P.-A. Métacognition et formation des enseignants. In La Métacognition et les Compétences Réflexives en Éducation; Lafortune, L., Mongeau, P., Pallascio, R., Eds.; Les Edition Logiques: Montréal, Italy, 1998; pp. 23-46.

36. Martin, D.; Doudin, P.-A. De l'utilité de la pensée réflexive pour améliorer l'efficacité de l'école. In Pour Une Pensée Réflexive en Éducation; Pallascio, R., Lafortune, L., Eds.; Québec Univerisity Press: Sainte-Foy, QC, Canada, 2000; pp. 47-67.

37. Loweald, H.D. Riflessioni Psicoanalitiche; Masson: Milano, Italy, 1999.

38. Stern, D.B. L' Esperienza non Formulata; Edizioni del Cerro: Tirrenia, Italy, 2007.

39. Winnicott, D. Playing \& Reality; Tavistock Publications: London, UK, 1971.

40. Maggiolini, A. Ruoli Affettivi e Psicoterapia; Franco Angeli: Milano, Italy, 2009.

41. Sandler, J. From Safety to Superego; Selected Papers of Joseph Sandler; Karnac Books: London, UK, 1988.

42. Bion, W. Experiences in Groups; Tavistock: London, UK, 1961.

43. Damiani, P. Embodied Cognition and Special Education Needs, in Gomez Paloma, Embodied Cognition: Theories and Applications in Education Science; Nova Science Publishers, Incorporated: New York, NY, USA, 2017.

44. Bruner, J.S. La Ricerca del Significato; Bollati Boringhieri: Torino, Italy, 1992.

45. Demetrio, D. Raccontarsi. L'autobiografia Come Cura di sè; Raffaello Cortina: Milano, Italy, 1996.

46. Smorti, A. Il Pensiero Narrativo. Costruzione di Storie e Sviluppo Della Coscienza Sociale; Giunti: Firenze, Italy, 1994.

47. Smorti, A. (a cura di), Il sé Come Testo; Giunti: Firenze, Italy, 1997.

48. Polkinghorne, D.E. Narrative Knowing and the Human Sciences; Albany: New York, NY, USA, 1988.

49. Gallese, V. The "Shared Manifold" Hypothesis: From mirror neurons to empathy. J. Conscious. Stud. 2001, $8,33-50$.

50. Gallese, V. The manifold nature of interpersonal relations: The quest for a common mechanism. Phil. Trans. Royal Soc. Lond. B 2003, 358, 517-528.

51. Gallese, V. Before and below Theory of mind: Embodied simulation and the neural correlates of social cognition. Proc. R. Soc. Biol. Biol. 2007, 362,659-669.

52. Rizzolatti, G. The mirror neuron system and imitation. In Perspectives on Imitation; Hurley, S., Chater, N., Eds.; MIT Press: Cambridge, UK, 2005; Volume 1

53. Contini M.G. Per una pedagogia delle emozioni, La Nuova Italia: Milano, Italy, 2001.

54. Mortari L.A. Apprendere dall'esperienza. Il pensare riflessivo nella formazione, Carocci, Roma, Italy, 2003.

55. Bove C. Ricerca educativa e formazione: contaminazioni metodologiche, Franco angeli: Milano, Italy, 2009 ; p. 96. 
56. Gallo Barbisio, C. La Rappresentazione del Paesaggio; Tirrenia Stampatori: Torino, Italy, 1999.

57. Gallo Barbisio, C. La Narrazione del Paesaggio; Tirrenia Stampatori: Torino, Italy, 2002.

58. Freedberg D. and Gallese V. Motion, emotion and empathy in esthetic experience. Trends Cogn. Sci. 2007, 11, 197-203.

59. Gallo Barbisio, C. Raccontami il tuo Paesaggio; Narrative Studies: Torino, Italy, 2009.

60. Blandino, G. Le Capacità Relazionali. Prospettive Psicodinamiche; Utet: Torino, Italy, 2012.

61. Imbasciati, A. Il Sistema Protomentale. Psicoanalisi Cognitiva; Origini, Costruzione e Funzionamento Della Mente, LED: Milano, Italy, 2006.

62. Mancia, M. Psicoanalisi e Neuroscienze; Springer Verlag: Milano, Italy, 2009.

(C) 2017 by the authors. Licensee MDPI, Basel, Switzerland. This article is an open access article distributed under the terms and conditions of the Creative Commons Attribution (CC BY) license (http://creativecommons.org/licenses/by/4.0/). 